\title{
Identity and some properties of the L-threonine aldolase activity manifested by pure 2-amino-3-ketobutyrate ligase of Escherichia coli
}

\author{
John P. Marcus and Eugene E. Dekker \\ Department of Biological Chemistry, The University of Michigan, Ann Arbor, MI (USA)
}

(Received 4 December 1992)

Key words: Threonine metabolism; L-Threonine dehydrogenase; 2-Amino-3-ketobutyrate ligase; L-Threonine aldolase; Glycine

\begin{abstract}
2-Amino-3-ketobutyrate ligase catalyzes the reversible, pyridoxal 5'-phosphate-dependent condensation of glycine with acetyl $\mathrm{CoA}$ forming the unstable intermediate, 2-amino-3-ketobutyrate. Several independent lines of evidence indicate that the pure protein obtained in the purification of this ligase from Escherichia coli also has L-threonine aldolase activity. The evidence includes: (a), a constant ratio of specific activities (aldolase/ligase) at all stages of purifying 2-amino-3-ketobutyrate ligase to homogeneity; (b), the same rate of loss of aldolase and ligase activities during controlled heat inactivation of the pure protein at $60^{\circ} \mathrm{C}$ in the absence, as well as in the presence of acetyl CoA, a protective substrate; (c), ratios of the two enzymic activities that are not significantly different during slow inactivation by iodoacetamide, with and without L-threonine added; (d), coincident rates of loss and essentially identical rates of recovery of aldolase activity and ligase activity during resolution of the holoenzyme with hydroxylamine followed by reconstitution with pyridoxal 5 '-phosphate. No aldolase activity is observed with D-threonine as substrate and L-allothreonine is about $25 \%$ as effective as L-threonine. Whereas ligase activity has a sharp pH optimum at 7.5 , the aldolase activity of this pure protein is maximal at pH 9.0. Comparative apparent $K_{\mathrm{m}}$ values for glycine (ligase) and L-threonine (aldolase) are $10 \mathrm{mM}$ and $0.9 \mathrm{mM}$, respectively, whereas corresponding respective $V_{\max }$ values were found to be 2.5 $\mu \mathrm{mol}$ of CoA released/min per mg vs. $0.014 \mu \mathrm{mol}$ of acetaldehyde formed (NADH oxidized) $/ \mathrm{min}$ per mg.
\end{abstract}

\section{Introduction}

Prior studies by numerous investigators have established that the catabolism of L-threonine by prokaryotes and/or eukaryotes is initiated by one of three enzymes, i.e., a dehydrogenase, an aldolase, and/or a dehydratase. Threonine dehydrogenase (EC 1.1.1.103), an $\mathrm{NAD}^{+}$-dependent enzyme, catalyzes the oxidation of $\mathrm{L}$-threonine to the unstable product, 2-amino-3-ketobutyrate, which compound in turn is the substrate for the pyridoxal 5'-phosphate-dependent enzyme, 2amino-3-ketobutyrate ligase (2-amino-3-ketobutyrate + $\mathrm{CoA} \rightleftharpoons$ acetyl $\mathrm{CoA}+$ glycine; 2-amino-3-oxobutanoate glycine-lyase (CoA-acetylating), EC 2.3.1.29). By this coupled sequence of reactions, L-threonine is efficiently converted in an $\mathrm{NAD}^{+}$-, pyridoxal 5'-phosphate- and CoA-dependent manner to glycine + acetyl CoA. In recent years, this pathway has been shown to be the primary route for threonine utilization in both

Correspondence to: E.E. Dekker, Department of Biological Chemistry/0606, The University of Michigan Medical School, 1301 Catherine Road, Ann Arbor, MI 48109-0606, USA. eukaryotes [1] and prokaryotes [2,3]. It accounts for $87 \%$ of the L-threonine degraded in the liver of normally fed rats [4], it is the only pathway for L-threonine degradation that is detected in chicken liver [5], and it is an effective alternate route for serine biosynthesis in Escherichia coli [6]. In earlier work, we succeeded in isolating both L-threonine dehydrogenase [3,7] and 2amino-3-ketobutyrate ligase [8] in homogeneous form from extracts of $E$. coli. The gene for each enzyme (designated $t d h$ and $k b l$, respectively) has been cloned and their primary structure, as well as that of each protein product has been determined $[9,10]$. The genes for these two enzymes make up the $t d h$ operon which lies within a 3.6-kb EcoRI fragment located at coordinate 81.2 of the $E$. coli genetic map [9]. The $k b l$ gene is immediately upstream of the $t d h$ gene within the same $E c o$ RI fragment and both genes are transcribed from a common promoter $[6,9,11]$. The operons of a multigene family which includes $t d h$, collectively known as the 'leucine regulon', are up- or down-regulated by Lleucine via a leucine-responsive regulatory protein encoded by the lrp gene. L-Leucine induces the activity of the $t d h$ operon about 7 -fold. 
L-Threonine aldolase (L-threonine acetaldehydelyase, EC 4.1.2.5) is also a pyridoxal 5'-phosphate-dependent enzyme which, as the name implies, catalyzes the aldol cleavage of this $\beta$-hydroxyamino-acid with formation of glycine plus acetaldehyde. Various investigators have shown that this aldolase activity is present in mammalian liver extracts, as well as in preparations obtained from both aerobic and anaerobic bacteria. Threonine aldolase has been crystallized from extracts of Candida humicola [12] and homogeneous samples of serine transhydroxymethylase from rabbit liver also have threonine aldolase activity [13].

In light of the importance that the threonine dehydrogenase /2-amino-3-ketobutyrate ligase enzyme couple has recently assumed in threonine metabolism, the considerable interest that exists in the regulatory aspects of the 'leucine regulon' which includes the $t d h$ operon, and the fact that the genes of these enzymes have been cloned and sizeable quantities of the two gene products can now be obtained in homogeneous state, we are carrying out indepth studies on structure/function interrelationships of each of these two enzymes. Such studies are aimed at elucidating specific amino-acid residues in the active site of each enzyme [14-18], as well as the metabolic/catalytic interplay of these two enzymes in the degradation and/or the biosynthesis of L-threonine. One aspect of studies in the latter area focused on the question of the coupled efficiency of the dehydrogenase/ligase-catalyzed reactions, which in turn related to determining the half-life of the unstable intermediate involved, namely, 2amino-3-ketobutyrate. To examine the stability of this $\alpha$-amino- $\beta$-ketoacid in solution, we generated a pool of 2-amino-3-ketobutyrate enzymically from L-threonine (using L-threonine dehydrogenase $+\mathrm{NAD}^{+}$). The concentration of 2-amino-3-ketobutyrate in this solution (which also contained unreacted threonine) was then determined as a function of time and $\mathrm{pH}$ by converting it to glycine (+ acetyl $\mathrm{COA}$ ) by the action of 2-amino3 -ketobutyrate ligase. The glycine so formed was quantitated by use of an amino-acid analyzer. Such studies (to be published) led us to discover that the ligase also catalyzes glycine formation from L-threonine. We report here that homogeneous preparations of $E$. coli 2-amino-3-ketobutyrate ligase express a low level of L-threonine aldolase activity; some properties of this activity are described.

\section{Materials and Methods}

Materials. Mutant E. coli SBD-76 cells were isolated and large quantities grown in a New Brunswick Fermacell fermentor as reported before $[3,19]$. DEAE-Sephadex, phenylagarose, yeast alcohol dehydrogenase, Dand L-threonine, iodoacetamide and acetyl $\mathrm{CoA}$ were purchased from Sigma. The following materials were obtained from the companies noted: Sephadex G-100 from Pharmacia; Bio-Gel HTP from Bio-Rad; DEAETrisacryl $M$ from LKB Instruments; Centricon-30 ultrafiltration units from Amicon; 5,5'-dithiobis-(2-nitrobenzoic acid) from Pierce; pyridoxal 5 '-phosphate from Nutritional Biochemicals; hydroxylamine $\cdot \mathrm{HCl}$ and $\mathrm{L}-$ allothreonine from Aldrich; D,L-allothreonine from Chemical Dynamics (Chemalog). All other chemicals were reagent grade.

Assay of 2-amino-3-ketobutyrate ligase and threonine aldolase activities. Ligase activity was measured spectrophotometrically at $412 \mathrm{~nm}$ by following the reaction of 5,5'-dithiobis-(2-nitrobenzoic acid) with the CoA released due to condensation of acetyl CoA with glycine; details of this procedure have been reported earlier for Assay I [8]. A molar extinction coefficient of $1.36 \cdot 10^{4} \mathrm{M}^{-1} \mathrm{~cm}^{-1}$ was used for 2-nitro-5-mercaptobenzoic acid [20]. One unit of ligase activity is defined as that amount which catalyzed the formation of 1 $\mu \mathrm{mol}$ of $\mathrm{CoA}$ per min at $25^{\circ} \mathrm{C}$. Threonine aldolase catalyzes the formation of acetaldehyde plus glycine; this activity was determined spectrophotometrically at $340 \mathrm{~nm}$ by coupling the reduction of acetaldehyde (oxidation of NADH) with yeast alcohol dehydrogenase. The assay mixture contained $100 \mathrm{mM}$ potassium phosphate buffer ( $\mathrm{pH} 8.0$ ), $10 \mathrm{mM}$ L-threonine, $0.2 \mathrm{mM} \mathrm{NADH}, 0.10 \mathrm{mg}(280 \mathrm{U} / \mathrm{mg}$ of protein) of yeast alcohol dehydrogenase, and ligase sample in a final volume of $1 \mathrm{ml}$. One unit of aldolase activity is the amount that catalyzed the formation of $1 \mu \mathrm{mol}$ of acetaldehyde ( $1 \mu \mathrm{mol}$ of $\mathrm{NADH}$ oxidized) per min at $25^{\circ} \mathrm{C}$; NADH was taken to have a molar extinction coefficient of $6.22 \cdot 10^{3}$. For both assays, specific activity is expressed as units per mg of protein. All spectrophotometric measurements were made with the use of a Cary 219 spectrophotometer equipped with a thermostated multicuvette changer. The level of protein in solution was determined quantitatively by the method of Lowry et al. [21] with crystalline bovine serum albumin as the standard.

\section{Results}

Purification of 2-amino-3-ketobutyrate ligase and $L$ threonine aldolase activities

Frozen E. coli SBD-76 cells (100 g wet weight; thawed overnight at $4^{\circ} \mathrm{C}$ ) were suspended in buffer, the suspension was subjected to sonic oscillation, and the extract thus obtained was fractionated by the multi-step procedure described before to purify 2-amino-3-ketobutyrate ligase [8]. Enzyme preparations used in these studies were homogeneous, showing one sharp protein band at $42 \mathrm{kDa}$ when subjected to polyacrylamide gel electrophoresis at $\mathrm{pH} 8.3$ in the presence of $1 \%$ sodium dodecyl sulfate. An accurate measure of ligase activity could not be determined in the crude extract or after 
the first two fractionation steps (i.e., an ammonium sulfate precipitation and elution from a column of Sephadex G-100) due to the presence of acetyl CoA deacylase activity. As a consequence, only purified protein fractions obtained after steps 4 through 7 were assayed for both ligase and threonine aldolase activities and the ratio of these activities calculated. As can be seen in Table I, although the specific activity values for the aldolase are some 100 -fold lower than for the ligase, the level of both activities increases in a similar manner throughout the fractionation procedures that yield one homogeneous protein and the ratio of the two activities remains virtually constant. Furthermore, the elution profiles for threonine aldolase activity from each of the four chromatographic columns listed were the same as those for ligase activity (data not shown).

\section{Controlled heat denaturation studies with the purified enzyme}

We subjected the purified enzyme solution (i.e., the DEAE-Trisacryl eluate) to heat treatment at $60^{\circ} \mathrm{C}$, at which temperature enzymic activity was slowly destroyed over a period of $30 \mathrm{~min}$. For this purpose, $2 \mathrm{ml}$ $(0.91 \mathrm{mg}$ of protein $/ \mathrm{ml})$ of the enzyme solution were placed in a hard-glass ignition test tube and heated in a constant-temperature water bath at $60^{\circ} \mathrm{C}$. The enzyme solution was stirred gently with a thermometer until the temperature reached $60^{\circ} \mathrm{C}$ where it remained constant. Aliquots $(260 \mu \mathrm{l})$ were removed at regular time intervals and immediately placed in a small test tube already chilled in ice. The level of the two enzymic activities that remained after each interval of heat treatment was measured and the ratio of specific activities calculated. The results listed in Table II show that the ratios remained essentially constant; since the levels of aldolase activity were very low after longer heat

\section{TABLE I}

2-Amino-3-ketobutyrate ligase and L-threonine aldolase activities throughout purification of the enzyme from extracts of $E$. coli

Complete details for purifying the enzyme to homogeneity have been presented before [8]. Enzymic activities were determined as described in Materials and Methods.

\begin{tabular}{|c|c|c|c|c|}
\hline \multirow[t]{2}{*}{ Purification step } & \multirow{2}{*}{$\begin{array}{l}\text { Protein } \\
\text { concentration } \\
(\mathrm{mg} / \mathrm{ml})\end{array}$} & \multicolumn{2}{|c|}{ Specific activity } & \multirow{2}{*}{$\begin{array}{l}\text { Ratio of } \\
\text { specific } \\
\text { activities } \\
(a / b)\end{array}$} \\
\hline & & $\begin{array}{l}\text { Aldolase } \\
\left(\times 10^{2}\right) \\
(a)\end{array}$ & $\begin{array}{l}\text { Ligase } \\
(b)\end{array}$ & \\
\hline $\begin{array}{l}\text { DEAE-Sephadex } \\
\text { eluate }\end{array}$ & 1.3 & 2.37 & 1.55 & 1.53 \\
\hline $\begin{array}{l}\text { Bio-gel-HTP } \\
\text { eluate }\end{array}$ & 1.6 & 2.30 & 1.72 & 1.34 \\
\hline $\begin{array}{l}\text { Phenylagarose } \\
\text { eluate }\end{array}$ & 0.9 & 3.30 & 2.40 & 1.38 \\
\hline $\begin{array}{l}\text { DEAE-Trisacryl } \\
\text { eluate }\end{array}$ & 0.8 & 4.23 & 3.02 & 1.40 \\
\hline
\end{tabular}

TABLE II

Controlled heat denaturation of E. coli 2-amino-3-ketobutyrate ligase and $L$-threonine aldolase activities

The two enzymic activities were assayed as described in Materials and Methods. The enzyme preparation used was the DEAE-Trisacryl eluate.

\begin{tabular}{|c|c|c|c|}
\hline \multirow{2}{*}{$\begin{array}{l}\text { Time heated } \\
\text { at } 60^{\circ} \mathrm{C} \\
(\mathrm{min})\end{array}$} & \multicolumn{2}{|c|}{ Specific activity } & \multirow{2}{*}{$\begin{array}{l}\text { Ratio of } \\
\text { specific } \\
\text { activities } \\
(a / b)\end{array}$} \\
\hline & $\begin{array}{l}\text { Aldolase } \\
\left(\times 10^{2}\right) \\
(a)\end{array}$ & $\begin{array}{l}\text { Ligase } \\
\text { (b) }\end{array}$ & \\
\hline 0 & 3.40 & 1.16 & 2.93 \\
\hline 1 & 2.87 & 1.14 & 2.52 \\
\hline 3 & 2.97 & 1.10 & 2.70 \\
\hline 6 & 2.41 & 1.06 & 2.27 \\
\hline 9 & 1.99 & 0.72 & 2.76 \\
\hline 15 & 1.02 & 0.45 & 2.27 \\
\hline
\end{tabular}

treatment (approx. 20\% activity remaining after 30 min), values for this activity became less precise toward the end causing some modest variation in the ratio.

In the same manner, $1.3 \mathrm{ml}(0.91 \mathrm{mg}$ of protein $/ \mathrm{ml})$ of the purified enzyme solution was subjected to controlled heat treatment at $60^{\circ} \mathrm{C}$ in the presence of the ligase substrate, acetyl CoA $(600 \mu \mathrm{M}$, final concentration). Aliquots of the solution were removed at given time intervals as before, the levels of aldolase and ligase activities were measured, and the ratio of the two activities again calculated. Whereas approx. $80 \%$ of the original enzymic activity was destroyed after 30 min in the previous heat-treatment experiment, in this case with acetyl CoA added only about a $40 \%$ decline in catalytic activity occurred and the ratio of the two specific activities was found to be $2.39,2.15,2.02,2.20$ and 2.39 after $0,5,10,15$ and $30 \mathrm{~min}$, respectively, of heat treatment.

\section{Inactivation studies with iodoacetamide}

We knew from other studies in our laboratory that reaction of $E$. coli 2-amino-3-ketobutyrate ligase with iodocetamide caused inactivation. Advantage was taken of this property to examine whether the two enzymic activities apparently catalyzed by this pure protein are affected in a similar manner. For this purpose, the 2-mercaptoethanol present in the buffer solution in which the purified enzyme was routinely stored was first removed by ultrafiltration through a Centricon- 30 membrane. Iodoacetamide, prepared in $20 \mathrm{mM}$ potassium phosphate buffer ( $\mathrm{pH} 8.0$ ) was then added (10 $\mathrm{mM}$, final concentration) to $1.7 \mathrm{ml}(0.91 \mathrm{mg}$ of protein $/ \mathrm{ml}$ ) of the enzyme solution. The reaction mixture was incubated in the dark at room temperature. At timed intervals, an aliquot of the reaction mixture was removed, 2-mercaptoethanol $(0.1 \mathrm{M}$, final concentration) was added to stop the reaction of iodoacetamide with the protein, and the mixture was again subjected 


\section{TABLE III}

Iodoacetamide inactivation of E. coli 2-amino-3-ketobutyrate ligase and $L$-threonine aldolase activities

Aldolase and ligase activities were measured as described in Materials and Methods; the enzyme preparation used was the DEAE-Trisacryl eluate.

\begin{tabular}{|c|c|c|c|}
\hline \multirow{2}{*}{$\begin{array}{l}\text { Reaction time } \\
\text { with iodoacet- } \\
\text { amide } \\
(\min )\end{array}$} & \multicolumn{2}{|c|}{ Specific activity } & \multirow{2}{*}{$\begin{array}{l}\text { Ratio of } \\
\text { specific } \\
\text { activities } \\
(a / b)\end{array}$} \\
\hline & $\begin{array}{l}\text { Aldolase } \\
\left(\times 10^{2}\right) \\
(a)\end{array}$ & $\begin{array}{l}\text { Ligase } \\
\text { (b) }\end{array}$ & \\
\hline 0 & 1.88 & 1.10 & 1.71 \\
\hline 10 & 1.40 & 0.75 & 1.87 \\
\hline 20 & 0.98 & 0.43 & 2.28 \\
\hline 30 & 0.71 & 0.40 & 1.78 \\
\hline 45 & 0.97 & 0.43 & 2.26 \\
\hline 60 & 0.50 & 0.22 & 2.27 \\
\hline
\end{tabular}

to Centricon ultrafiltration to remove small molecular reactants and reagents. The treated enzyme was then taken up in $20 \mathrm{mM}$ potassium phosphate buffer $(\mathrm{pH}$ 7.2) and the levels of ligase and aldolase activities determined. The results given in Table III show that reaction with iodoacetamide for $60 \mathrm{~min}$ under these experimental conditions caused a $70-80 \%$ loss of original enzymic activity and that during the course of this inactivation the ratio of the two catalytic activities, although a little variable because of the experimental manipulations involved and the low level of aldolase activity remaining at the end, are overall reasonably constant.

The very same experiment was repeated in which the reaction with iodoacetamide $(10 \mathrm{mM}$ final concentration) was carried out in the presence of L-threonine (25 $\mathrm{mM}$ final concentration). Under these conditions, only a $20 \%$ loss of catalytic activity was observed after reaction of the enzyme with iodoacetamide for $60 \mathrm{~min}$ and the ratios of aldolase to ligase activity again were quite constant (range $2.87 \pm 0.41$ ) when measured at six separate time points.

Studies involving resolution of pyridoxal 5'-phosphate from the purified enzyme and reconstitution of the holoenzyme

Earlier studies $[8,17]$ established that E. coli 2amino-3-ketobutyrate ligase is a homodimeric, pyridoxal phosphate-dependent enzyme; 1 mol of coenzyme is bound per ligase subunit and the holoenzyme can be resolved and reconstituted. This being true, we examined whether resolution and reconstitution of the holoenzyme affected the ligase and aldolase activities of this protein in a similar manner. To resolve the holoenzyme, individual samples of pure ligase $(0.80 \mathrm{mg}$ of protein $/ \mathrm{ml}$ ) were dialyzed separately for varying intervals of time at $4^{\circ} \mathrm{C}$ against $20 \mathrm{mM}$ potassium phosphate buffer $(\mathrm{pH} 7.2)$ containing $5 \mathrm{mM}$ hydroxyl- amine plus $10 \%$ glycerol and $1 \mathrm{mM} 2$-mercaptoethanol. Each sample was subsequently dialyzed extensively against the same buffer solution containing no hydroxylamine. Ligase so treated over a period of $4 \mathrm{~h}$ showed a nearly complete and coincident loss of both ligase and threonine aldolase activities (Fig. 1); a similar loss of absorptivity at $428 \mathrm{~nm}$ was also seen. When the spectra of the native, untreated ligase and this hydroxylamine-resolved apoenzyme were measured side-by-side between 350 and $500 \mathrm{~nm}$, the former sample showed the typical absorption curve with a $\lambda_{\max }$ of $428 \mathrm{~nm}$, whereas virtually no absorption over this spectral range was evident for the latter (data not shown). When the hydroxylamine-resolved ligase was incubated at $25^{\circ} \mathrm{C}$ in $20 \mathrm{mM}$ potassium phosphate buffer $(\mathrm{pH} \mathrm{7.2)}$ containing $20 \mu \mathrm{M}$ pyridoxal 5'-phosphate plus $10 \%$ glycerol and $1 \mathrm{mM}$ 2-mercaptoethanol, the enzyme again showed a time-dependent, parallel recovery of ligase activity, threonine aldolase activity, and 428-nm absorptivity as seen before (see Fig. 4 in Ref. 8). A spectrum of this reconstituted enzyme also showed the expected absorption curve with a maximum at $428 \mathrm{~nm}$.

Substrate preference of the threonine aldolase activity

Whereas past studies had shown that homogeneous samples of $E$. coli 2-amino-3-ketobutyrate ligase could utilize n-propionyl $\mathrm{CoA}$ and n-butyryl $\mathrm{CoA}$ beside acetyl CoA as substrates, the enzyme is absolutely specific for glycine [8]. The specificity of the aldolase activity of this pure protein was tested here with those analogs of threonine that were commercially available. The assay mixtures contained $100 \mathrm{mM}$ potassium phosphate buffer ( $\mathrm{pH} 8.0$ ), $0.2 \mathrm{mM}$ NADH, $0.10 \mathrm{mg}$ of yeast alcohol dehydrogenase, $0.091 \mathrm{mg}$ of ligase, and a threonine substrate $(10 \mathrm{mM}$ final concentration in each case) in a final volume of $1 \mathrm{ml}$. Rates of reactions were

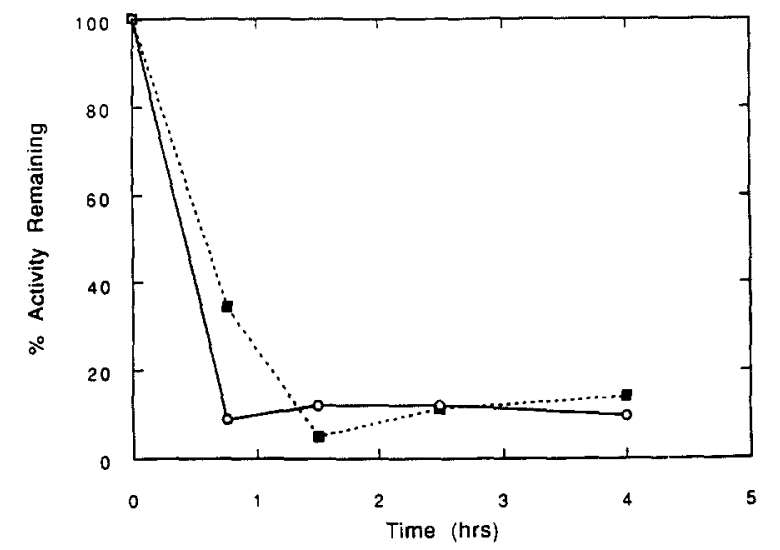

Fig. 1. Effect of holoenzyme resolution on the L-threonine aldolase activity of $E$. coli 2-amino-3-ketobutyrate ligase. The DEAE-Trisacryl enzyme preparation was used for these studies. Experimental details describing how the holoenzyme was resolved with hydroxylamine are given in the text. (O), Ligase activity; ( $\boldsymbol{\sigma})$, aldolase activity. 


\section{TABLE IV}

Substrate specificity of $L$-threonine aldolase activity expressed by 2 amino-3-ketobutyrate ligase of $E$. coli

The homogeneous enzyme obtained after chromatography on a DEAE-Trisacryl column was used in each case. Assay conditions are described in the text, the results shown are an average of duplicate experiments.

\begin{tabular}{lll}
\hline Substrate tested & $\begin{array}{l}\text { Specific activity } \\
\left(\times 10^{2}\right)\end{array}$ & $\begin{array}{l}\text { Relative } \\
\text { activity }(\%)\end{array}$ \\
\hline L-Threonine & 4.91 & 100 \\
D,L-Allothreonine & 1.23 & 25 \\
L-Allothreonine & 1.32 & 27 \\
D-Threonine & 0 & 0 \\
\hline
\end{tabular}

followed at $25^{\circ} \mathrm{C}$. As can be seen in Table IV, although no activity is observed with D-threonine as substrate, $\mathrm{L}$-allothreonine is approx. $25 \%$ as effective as is $\mathrm{L}$ threonine.

pH-Dependence and kinetic constants for the L-threonine aldolase activity

The threonine aldolase activity catalyzed by purified E. coli 2-amino-3-ketobutyrate ligase was found to have a fairly sharp optimum at pH 9.0 (Fig. 2). The apparent Michaelis constant and maximum velocity with L-threonine as substrate were also determined. Essentially the same assay mixture as described immediately before was used, except that potassium phosphate buffer at $\mathrm{pH} 8.5$ was used and final $\mathrm{L}$-threonine concentrations within the range of 2.5 to $20 \mathrm{mM}$ were tested. Kinetic constants were calculated from experimental data obtained by Lineweaver-Burk plots [22] using a computer-assisted linear least-squares fit; as-

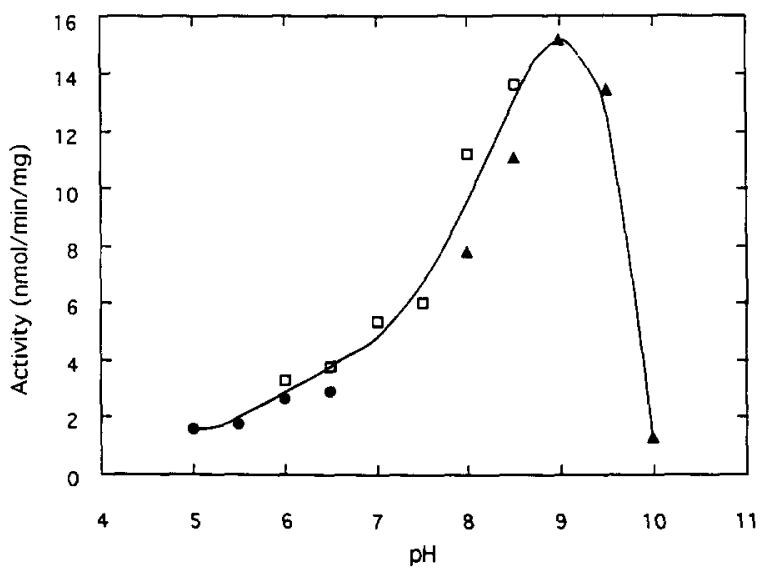

Fig. 2. Threonine aldolase activity of E. coli 2-amino-3-ketobutyrate ligase as a function of $\mathrm{pH}$. The enzyme used was the DEAE-Trisacryl eluate; activity was measured at $25^{\circ} \mathrm{C}$ by the usual spectrophotometric assay with yeast alcohol dehydrogenase. Buffers used to cover the $\mathrm{pH}$ range shown were: $0.5 \mathrm{M}$ Mes (2- $(N$-morpholino)ethanesulfonic acid), $\mathrm{pH} 5.0$ to $6.5(\bullet) ; 1 \mathrm{M}$ potassium phosphate, $\mathrm{pH}$ 6.0 to 8.5 ( $\square)$; $0.5 \mathrm{M}$ Ches (2-( $N$-cyclohexylamine)ethanesulfonic acid), $\mathrm{pH} 8.0$ to 10.0 ( $A$ ). says were run in triplicate at each of the six concentrations of L-threonine tested. Under these experimental conditions, the enzyme was determined to have a $K_{\mathrm{m}}$ value of $0.9 \mathrm{mM}$ for L-threonine and a $V_{\max }$ of 0.014 $\mu \mathrm{mol}$ of $\mathrm{NADH}$ oxidized/min per mg. These values compare with a $K_{\mathrm{m}} \cong 10 \mathrm{mM}$ for glycine and a $V_{\max } \cong$ $2.5 \mu \mathrm{mol}$ of $\mathrm{CoA}$ released/min per $\mathrm{mg}$ in the ligase reaction catalyzed by this enzyme.

\section{Discussion}

Detection and characterization of threonine aldolase activity in various animal preparations would appear to take first place in the discovery of the three enzyme-catalyzed reactions currently known to initiate threonine catabolism. In 1949, Braunstein and Vilenkina [23] reported the presence of activity that catalyzed the aldol cleavage of $\beta$-hydroxyamino acids; in another paper that same year, Vilenkina [24] established that glycine and acetaldehyde were the products of threonine breakdown. Such reports led to the first partial purification (5-6-fold) and characterization of threonine aldolase from extracts of rat liver by Lin and Greenberg [25].

Since such early observations were made, threonine aldolase has had something of a mixed history as to identity and physiological significance. It has been detected in and purified to different levels from extracts (primarily liver) of various animal species [26,27], as well as of aerobic $[28,29]$ and anaerobic $[30-32]$ bacteria. Homogeneous crystalline enzyme has been obtained from extracts of Candida humicola [33,34]. Some of these reports indicate a single enzyme utilizes both L-threonine and L-allothreonine as substrates, a few claim only L-threonine is effective, while yet others present evidence for two distinct enzymes that cleave threonine and allothreonine. In a fairly recent paper [35], Yeung asserts that the method of assay can confuse the detection of putative aldolase activity with threonine dehydratase activity and that there is no threonine aldolase in cytosolic liver extracts from normal or starved rats. Such mixed reports are augmented by the work of Schirch and Gross [13], which has been confirmed by others [36], who showed that homogeneous preparations of rabbit liver serine transhydroxymethylase also have threonine/allothreonine aldolase activity. Along similar lines, Palekar et al. [37] established the identity of cytoplasmic serine transhydroxymethylase and allothreonine aldolase with rat liver aminomalonate decarboxylase; the final homogeneous enzyme preparation exhibited no activity towards Lthreonine.

When considered collectively, several independent lines of evidence presented here establish that the protein obtained in homogeneous form during purification of 2-amino-3-ketobutyrate ligase from $E$. coli also 
catalyzes the aldol cleavage of threonine. Although it seems likely that the activity associated with 2-amino3-ketobutyrate ligase accounts for essentially all threonine aldolase activity in $E$. coli, it was not possible to determine this experimentally by the two enzyme assays we used. Measuring aldolase activity (by NADH oxidation at $340 \mathrm{~nm}$ with alcohol dehydrogenase) is inaccurate in relatively crude protein fractions due to the presence of NADH-oxidizing enzymes; likewise, ligase activity cannot be determined (by following the condensation of acetyl CoA with glycine) in comparable prepararations due to the presence of high levels of acetyl CoA deacylase activity. As noted earlier in this paper, the presence of threonine aldolase activity was first considered and subsequently confirmed when unsatisfactory quantitative data were obtained in studies in which we were measuring the concentration/stability of 2-amino-3-ketobutyrate in reaction mixtures that also contained L-threonine. Although the actual level of threonine aldolase activity is approx. 100 -fold lower than the ligase activity, it is a factor to be considered when reaction mixtures containing this enzyme are incubated for longer periods of time and since the $K_{\mathrm{m}}$ value for L-threonine (aldolase activity) is significantly lower than that for glycine (ligase activity). Aldolase activity associated with rabbit liver serine transhydroxymethylase is more active with allothreonine than with L-threonine [13] whereas that same activity catalyzed by rat liver aminomalonate decarboxylase utilizes only allothreonine as substrate [37]. In contrast, the aldolase activity of $E$. coli 2-amino-3-ketobutyrate ligase is most active with L-threonine; L-allothreonine is about $25 \%$ as effective as a substrate. This report, therefore, presents yet a third instance of a homogenous, pyridoxal 5 '-phosphate-dependent enzyme (now including $E$. coli 2-amino-3-ketobutyrate ligase, rabbit liver serine transhydroxymethylase, and rat liver aminomalonate decarboxylase; glycine is a substrate or product for all three) which is also an aldolase towards threonine and/or allothreonine.

\section{Acknowledgements}

This investigation was supported by a research grant (DK-03718) from the National Institute of Diabetes and Digestive and Kidney Diseases, U.S. Public Health Service. J.P.M. was a predoctoral trainee of National Institutes of Health National Research Service Award S-T32-GM07767. The authors gratefully acknowledge the excellent technical assistance that was provided by Ashley A. Abel in this work.

\section{References}

1 Dale, R.A. (1978) Biochim. Biophys. Acta 544, 496-503.

2 Komatsubara, S., Murata, K., Kisumi, M. and Chibata, I. (1978) J. Bacteriol. 135, 318-323.

3 Boylan, S.A. and Dekker, E.E. (1981) J. Biol. Chem. 256, 18091815.

4 Bird, M.I. and Nunn, P.B. (1983) Biochem. J. 214, 687-694.

5 Aoyama, Y. and Motokawa, Y. (1981) J. Biol. Chem. 256, 1236712373.

6 Ravnikar, P.D. and Somerville, R.L. (1987) J. Bacteriol. 169, 2611-2617.

7 Craig, P.A. and Dekker, E.E. (1986) Biochemistry 25, 1870-1876.

8 Mukherjee, J.J. and Dekker, E.E. (1987) J. Biol. Chem. 262, 14441-14447.

9 Aronson, B.D., Somerville, R.L., Epperly, B.R. and Dekker, E.E. (1989) J. Biol. Chem. 264, 5226-5232.

10 Aronson, B.D., Ravnikar, P.D. and Somerville, R.L. (1988) Nucleic Acids Res. 16, 3586.

11 Ravnikar, P.D. and Somerville, R.L. (1987) J. Bacteriol. 169, 4716-4721.

12 Kumagai, H., Nagate, T., Yoshida, H. and Yamada, H. (1972) Biochim. Biophys. Acta 258, 779-790.

13 Schirch, L. and Gross, T. (1968) J. Biol. Chem. 243, 5651-5655.

14 Epperly, B.R. and Dekker, E.E. (1989) J. Biol. Chem. 264, 18296-18301.

15 Craig, P.A. and Dekker, E.E. (1990) Biochim. Biophys. Acta 1037, 30-38.

16 Epperly, B.R. and Dekker, E.E. (1991) J. Biol. Chem. 266, 6086-6092.

17 Mukherjee, J.J. and Dekker, E.E. (1990) Biochim. Biophys. Acta $1037,24-29$.

18 Mukherjee, J.J. and Dekker, E.E. (1992) Arch. Biochem. Biophys. 299, 147-153.

19 Boylan, S.A. and Dekker, E.E. (1983) J. Bacteriol. 156, 273-280.

20 Ellman, G.L. (1959) Arch. Biochem. Biophys. 82, 70-77.

21 Lowry, O.H., Rosebrough, N.J., Farr, A.L. and Randall, R.J. (1951) J. Biol. Chem. 193, 265-275.

22 Lineweaver, H. and Burk, D. (1934) J. Am. Chem. Soc. 56, 658-661.

23 Braunstein, A.E. and Vilenkina, G.Y. (1949) Doklady Akad. Nauk. S.S.S.R. 66, 1243-1247.

24 Vilenkina, G.Y. (1949) Doklady Akad. Nauk. S.S.S.R. 69, 385388.

25 Lin, S. and Greenberg, D.M. (1954) J. Gen. Physiol. 38, 181-188.

26 Karasek, M.A. and Greenberg, D.M. (1957) J. Biol. Chem. 227, 191-205.

27 Pagani, R., Leoncini, R., Terzuoli, L., Chen, J., Pizzichini, M. and Marinello, E. (1991) Biochem. Soc. Trans. 19, 346S.

28 Morris, J.G. (1969) Biochem. J. 115, 603-605.

29 Bell, S.C. and Turner, J.M. (1977) Biochem. J. 166, 209-216.

30 Dainty, R.H. (1970) Biochem J. 117, 585-592.

31 Jungermann, K.A., Schmidt, W., Kirchniawy, F.H., Rupprecht, E.H. and Thauer, R.K. (1970) Eur. J. Biochem. 16, 424-429.

32 Stocklein, W. and Schmidt, H.L. (1985) Biochem. J. 232, 621-622.

33 Yamada, H., Kumagai, H., Nagate, T. and Yoshida, H. (1970) Biochem. Biophys. Res. Commun. 39, 53-58.

34 Kumagai, H., Nagate, T., Yoshida, H. and Yamada, H. (1972) Biochim. Biophys. Acta 258, 779-790.

35 Yeung, Y.G. (1986) Biochem. J. 237, 187-190.

36 Akhtar, M. and El-Obeid, H.A. (1972) Biochim. Biophys. Acta 258, 791-799.

37 Palekar, A.G., Tate, S.S. and Meister, A. (1973) J. Biol. Chem. $248,1158-1167$. 